\title{
Römische Wertbegriffe: Wissenschaftsgeschichtliche Anmerkungen aus althistorischer Sicht
}

\author{
STEFAN REBENICH (BIELEFELD)
}

Es war Martin Heidegger, der 1943 die Ursprünge der Wertphilosophie präzise benannt hat. „Im 19. Jahrhundert wird die Rede von den Werten geläufig und das Denken in Werten üblich. Aber erst zufolge einer Verbreitung der Schriften Nietzsches ist die Rede von Werten populär geworden. Man spricht von Lebenswerten, von den Kulturwerten, von Ewigkeitswerten, von der Rangordnung der Werte, von geistigen Werten, die man z. B. in der Antike zu finden glaubte. Bei der gelehrten Beschäftigung mit der Philosophie und bei der Umbildung des Neukantianismus kommt man zur Wert-Philosophie. Man baut Systeme von Werten und verfolgt in der Ethik die Schichtungen von Werten. Sogar in der christlichen Theologie bestimmt man Gott, das summum ens qua summum bonum, als den höchsten Wert. Man hält die Wissenschaft für wertfrei und wirft die Wertungen auf die Seite der Weltanschauungen. Der Wert und das Werthafte wird zum positivistischen Ersatz für das Metaphysische." $" 1$

Damit ist ein Problemkomplex angesprochen, der in den deutschen Kultur- und Geisteswissenschaften um die Jahrhundertwende unter dem Schlagwort ,Historismus" diskutiert wurde. ${ }^{2}$ Vor dem Hintergrund dieser Debatte müssen die Anfänge der altertumswissenschaftlichen, insbesondere der latinistischen Wertforschung rekonstruiert werden. In einem ersten Schritt (I.) ist deutlich zu machen, daß Philologen und Historiker zunächst nicht römische Wertbegriffe, sondern nur lateinische Begriffe untersuchten. Hier gilt es zu fragen, weshalb die um 1900 vom Historismusstreit erschütterte Altertumswissenschaft sich verstärkt der Begriffsgeschichte zuwandte und welche innovativen Potentiale dadurch freigesetzt wurden. In einem zweiten Schritt (II.) müssen im Anschluß an Peter Lebrecht Schmidt ${ }^{3}$ die

${ }^{1}$ M. HeIDEgGER, Nietzsches Wort "Gott ist tot" [1943], zitiert nach DERS., Holzwege, Frankfurt a. M. 1950, 193-247, hier 209f. Vgl. C. SCHMITT, Die Tyrannei der Werte [1959], in: Säkularisation und Utopie. Ebracher Studien. Ernst Forsthoff zum 65. Geburtstag, Stuttgart u. a. 1967, 37-62, hier 53.

${ }^{2} \mathrm{Vgl}$. S. REBENICH, Orbis Romanus. Deutungen der römischen Geschichte im Zeitalter des Historismus, in: K. NoWAK u. a. (Hgg.), Adolf von Harnack. Christentum, Wissenschaft und Gesellschaft, Göttingen 2003, 29-49 sowie DERS., Art. „Historismus I. Allgemein“, in: Der Neue Pauly 14 (2000), 469-485 mit weiterer Literatur.

${ }^{3}$ Vgl. den Beitrag von P. L. SCHMIDT, Zwischen Werttheorie, Begriffsgeschichte und Römertum (in diesem Band), 3-22. 
Ursachen, Voraussetzungen und Folgen der latinistischen und althistorischen Wertforschung präzisiert werden. In einem weiteren Kapitel (III.) sollen die Charakteristika der begriffsgeschichtlichen Forschung im „Dritten Reich" benannt werden. Dann (IV.) gilt das Augenmerk den methodischen und inhaltlichen Defiziten der Wertforschung innerhalb einer konservativ ausgerichteten und wissenschaftstheoretisch abstinenten Latinistik nach 1945. Zum Vergleich werde ich (V.) die Entwicklung der althistorischen Begriffsgeschichte nach dem Ende des Zweiten Weltkrieges skizzieren. Ich schließe (VI.) meine Ausführungen mit einem kurzen Plädoyer für eine interdisziplinäre Begriffsgeschichte, die - wissenschaftsgeschichtlich sensibilisiert - das methodisch obsolete Paradigma der Wertforschung überwindet.

\section{Am Anfang war das Wort: Der „Thesaurus linguae Latinae“ und die Begriffsgeschichte}

$\mathrm{Zu}$ den gigantischen Gemeinschaftsunternehmen, die Ende des 19. Jahrhunderts das gesamte Erbe der Alten Welt erfassen sollten, zählte auch der „Thesaurus linguae Latinae“, den zu erstellen sich 1893 die fünf deutschsprachigen Akademien Berlin, Göttingen, Leipzig, München und Wien entschlossen hatten. ${ }^{4}$ Der erste Faszikel erschien mitten in der Krise der Fakultäten, nämlich im Jahr 1900, und reichte bis absurdus. Spezielle grammatische, sprachgeschichtliche und lexikographische Probleme, die für die Lemmata des "Thesaurus“ einschlägig waren, wurden in dem von Eduard Wölfflin herausgegebenen „Archiv für Lateinische Lexikographie“ veröffentlicht. Hier demonstrierte eine lange Reihe von Philologen an einzelnen Wörtern und Wortgruppen, „welche Erkenntnisfortschritte gezieltes Suchen und Auswerten des Sprachmaterials" erbringen konnte. ${ }^{5}$ Ein Beispiel ist der von Richard Heinze 1908 publizierte Beitrag über „Supplicium", ${ }^{6}$ der den Vorgaben der Zeitschrift folgte und eine erschöpfende lexikographische Untersuchung des Wortes lieferte.

${ }^{4}$ Vgl. S. REBENICH, „Mommsen ist er niemals näher getreten“. Theodor Mommsen und Hermann Diels, in: W. M. CALDER III, J. MANSFELD (Hgg.), Hermann Diels (18481922) et la science de l'Antiquité, Genf 1999, 85-142, hier $122 \mathrm{ff}$. mit weiterer Literatur sowie allg. DERS., Die Altertumswissenschaften und die Kirchenväterkommission an der Akademie: Theodor Mommsen und Adolf Harnack, in: J. KoCKA (Hg.), Die Königlich Preußische Akademie der Wissenschaften zu Berlin im Kaiserreich, Berlin 1999, 199233.

${ }^{5}$ D. KRÖMER (Hg.), Wie die Blätter am Baum, so wechseln die Wörter. 100 Jahre Thesaurus linguae Latinae, Stuttgart/Leipzig 1995, 17.

${ }^{6}$ Zitiert nach R. HEINZE, Vom Geist des Römertums, hg. von E. BURCK, Darmstadt ${ }^{4} 1972,28-42$. 
Der „Thesaurus linguae Latinae“ bot die notwendige organisatorische Voraussetzung für den Aufschwung begriffsgeschichtlicher Studien seit 1900, die die Entwicklung der Begriffsbedeutungen und die Konstanz oder den Wandel des ursprünglichen Begriffsgehaltes untersuchten. Die altertumswissenschaftliche Lexikographie, die seit dem Humanismus systematisch betrieben wurde, konnte dadurch auf eine völlig neue Grundlage gestellt werden. Der aus dem Geist des Positivismus geborene "Thesaurus“" ermöglichte die systematische Sammlung und Bearbeitung des Materials, bot mit dem "Archiv für Lateinische Lexikographie" ein wichtiges Publikationsorgan und stellte eine effiziente Wissenschaftsinfrastruktur zur Verfügung. Im Rahmen der begriffsgeschichtlichen Arbeit wurden selbstverständlich auch Wörter und Wortgruppen untersucht, die später unter der Rubrik „Wertbegriffe“ subsumiert wurden. Wenn man sich denn überhaupt auf die beschwerliche Suche nach einem ,primus inventor der latinistischen Wertforschung machen will, dann sollte man in der Tat nicht nur einzelne Personen, sondern auch die institutionellen Rahmenbedingungen berücksichtigen. ${ }^{7}$

Doch mit dem Hinweis auf den „Thesaurus“ allein ist der Aufschwung begriffsgeschichtlicher Forschung, der keineswegs nur die deutsche Altertumsforschung ergriff, ${ }^{8}$ nicht hinlänglich zu erklären. Die Sammlungen des "Thesaurus" bildeten die Grundlage für innovative Studien. Richard Reitzenstein und Eduard Fraenkel versuchten, wie Gabriele Thome gezeigt ${ }^{9}$ und Peter Lebrecht Schmidt differenzierend dargestellt hat, ${ }^{10}$ mit ihren begriffsgeschichtlichen Arbeiten über humanitas ${ }^{11}$ und fides ${ }^{12}$ den analytischhistorischen Empirismus der sterilen „Thesaurus"-Arbeit zu überwinden. ${ }^{13}$ Reitzensteins Untersuchung über die „Sprache der lateinischen Erotik“ erschien im selben Jahr wie Matthias Gelzers große Studie zur Nobilität der römischen Republik: 1912. Der Althistoriker Gelzer benutzte die Begriffsgeschichte, um sich mit sozialhistorischer Intention von Mommsens Insti-

${ }^{7}$ G. THOME, Zentrale Wertvorstellungen der Römer. Texte, Bilder, Interpretationen, 2 Bde., Bamberg 2000, Bd. 1, $7 f$.

${ }^{8}$ Als Beispiel aus der angelsächsischen Forschung sei angeführt: H. W. LiTCHFIELD, National exempla virtutis in Roman Literature, $\mathrm{HSPh} 25,1914,1-71$.

${ }^{9}$ THOME (wie Anm. 7), Bd. 1, 7f. und 17-19.

${ }^{10}$ Vgl. SCHMIDT (wie Anm. 3).

${ }^{11}$ R. REITZENSTEIN, Werden und Wesen der Humanität im Altertum, Straßburg 1907.

${ }^{12}$ E. FRAENKEL, Zur Geschichte des Wortes fides, RhM 71, 1916, 187-199.

${ }^{13}$ Damit trugen sie auch zur disziplinären Emanzipation der Latinistik bei; vgl. C. J. CLASSEN, Virtutes Romanorum nach dem Zeugnis der Münzen republikanischer Zeit, MDAI(R) 93, 1986, 257-279, hier 258f. (= DERS., Die Welt der Römer. Studien zu ihrer Literatur, Geschichte und Religion, hg. von M. VIELBERG, Berlin/New York 1993, 39-61, hier 39f.). 
tutionengeschichte $\mathrm{zu}$ emanzipieren, ${ }^{14}$ und auch Reitzenstein distanzierte sich von einer formalistischen, an juristischer Argumentation geschulten und reduktionistischen Interpretation römischer Bezeichnungen für die soziale Kommunikation. Von Wertbegriffen ist hier selbstverständlich nicht die Rede.

Der Aufstieg der latinistischen Begriffsgeschichte fällt folglich mit der Abkehr von Mommsens Rekonstruktion des römischen Staates zusammen. Der Mommsenschüler Heinze forderte die kulturhistorische Öffnung der Literaturgeschichtsschreibung und berief sich auf Mommsens „Römische Geschichte“. Statt der juristischen Systematisierung, die der alte Mommsen mit seinem „Römischen Staatsrecht" betrieb, bevorzugte Heinze die historiographie engagée des jungen Historikers. ${ }^{15}$ Doch auch bekennende Historisten begeisterten sich für die Begriffsgeschichte. So forderte der Kirchenhistoriker Adolf von Harnack im Anschluß an die von Gustav Teichmüller entwickelte Theorie der Begriffe, ${ }^{16}$ historisch-kritische Untersuchungen müßten den ursprünglichen Inhalt einzelner zentraler Begriffe ermitteln, da dieser im Laufe der Zeit verhüllt worden sei. Nur so könne die theologische Terminologie der frühen Kirche überzeugend rekonstruiert werden. ${ }^{17}$

Eine historistisch arbeitende Begriffsgeschichte wollte die historistische Relativierung der Werte und Normen überwinden und Begriffe ermitteln, die Maßstäbe zur Beurteilung historischer Auffassungen geben und den „bleibenden und lebensvollen Gedankenformen"18 zur Anerkennung verhelfen sollten. Der Neukantianer Wilhelm Windelband bemühte sich um die Begründung einer philosophischen Begriffsgeschichte, die sich ,allgemeingültigen Begriffen der Weltauffassung und Lebensbeurteilung“ widmete

${ }^{14}$ M. GELZER, Die Nobilität der römischen Republik, Leipzig 1912 (= DERS., Kleine Schriften, Bd. 1, Wiesbaden 1962, 17-135). Vgl. H. FuCHS, Begriffe römischer Prägung, MH 4, 1947, 157-158, zitiert nach H. OPPERMANN (Hg.), Römische Wertbegriffe, Darmstadt 1983, 23-41, hier 23, sowie allg. K. CHRIST, Römische Geschichte und deutsche Geschichtswissenschaft, München 1982, $113 \mathrm{ff}$.

${ }^{15}$ R. HEINZE, Die gegenwärtigen Aufgaben der römischen Literaturgeschichte, Neue Jahrbücher für das Klassische Altertum, Geschichte und deutsche Literatur 19, 1907, 161 175, hier 174f. Zu Mommsens „Römischer Geschichte" vgl. S. REBENICH, Theodor Mommsens „Römische Geschichte“, erscheint in: E. STEIN-HöLKESKAMP, K.-J. HöLKESKAMP (Hgg), Erinnenungsorte der römischen Antike. Rom und sein Imperium, München 2005.

${ }^{16}$ G. TEICHMÜLleR, Neue Studien zur Geschichte der Begriffe, 3 Bde., Gotha 1876 (Ndr. Hildesheim 1965).

${ }^{17}$ A. vON HARNACK, Die Terminologie der Wiedergeburt und verwandter Erlebnisse in der älteren Kirche, Texte und Untersuchungen zur Geschichte der altchristlichen Literatur 42.3, 1918, 97-143.

${ }^{18}$ TEICHMÜlLER (wie Anm. 16), Bd. 3, IX. 
und die Philosophie in die Lage versetzen sollte, „in der Formung ihrer Probleme und Begriffe ... das nur historisch Geltende der Veranlassungen und Vermittlungen von dem an sich Geltenden der Vernunftwahrheit" abzulösen „und von dem Zeitlichen zu dem Ewigen“" vorzudringen. ${ }^{19}$

\section{Die Wertforschung: Menschen statt Institutionen}

„Wenn Theodor Mommsen erklärte, Rom danke seine Größe lediglich dem energisch durchgeführten System der politischen Zentralisierung - so werden wir von dem sachkundigen antiken Beobachter [scil. Polybios] einerseits, von dem größten römischen Historiker der Neuzeit andrerseits wie immer auch hier Wichtiges zu lernen haben. Aber: Institutionen, mögen sie noch so wichtig und folgenreich sein, können doch niemals als primäre Ursachen politischer Entwickelungen gelten; hinter ihnen stehen die Menschen, die sie geschaffen, erhalten und getragen haben. ${ }^{620}$ Richard Heinze formulierte in seiner Rektoratsrede von 1921 „Von den Ursachen der Größe Roms" programmatisch seine Sicht der römischen Geschichte, die sich grundlegend von Mommsens Institutionengeschichte unterschied. Damit wandte er sich, wie zuvor bereits Reitzenstein und Gelzer, nicht nur gegen Mommsens abstrahierendes System des römischen Staatsrechts, sondern auch gegen dessen Wissenschaftsverständnis.

Mommsen war einst erfolgreich ausgezogen, um ,die Archive der Vergangenheit $\mathrm{zu}$ ordnen" ${ }^{\text {"21 }}$ und hatte zu diesem Zweck den Großbetrieb der Altertumswissenschaft geschaffen, der die Leistungsfähigkeit der historisch-kritischen Methode eindrucksvoll bestätigte, in dem aber Heuristik und Interpretation auseinanderfielen und der den Gelehrten in einen Arbeiter und Kärrner verwandelte. ${ }^{22}$ Die Wissenschaft schien nichts mehr mit dem Leben zu tun zu haben. Diesen Preis einer durchaus erfolgreichen Modernisierung wollten viele, gerade jüngere Gelehrte nicht zahlen.

Nicht nur die Philosophie, auch andere geisteswissenschaftliche Disziplinen wandten sich gegen eine historistische Wissenschaft und ihre

${ }^{19}$ W. WindelBand, Lehrbuch der Geschichte der Philosophie, 1. Aufl. 1891 (zitiert nach der 5. Aufl. Straßburg 1910), VII; vgl. auch DERS. (Hg.), Die Philosophie im Beginn des zwanzigsten Jahrhunderts, 2. Aufl. Heidelberg 1907 sowie H. G. MEIER, Art. „Begriffsgeschichte“, in: Historisches Wörterbuch der Philosophie 1 (1971), 788-808, hier 804.

${ }^{20}$ R. HEINZE, Von den Ursachen der Größe Roms, zitiert nach DERS. (wie Anm. 6), 10. Vgl. dazu A. PERUTELLI, Richard Heinze e i Wertbegriffe, QS 3.6, 1977, 51-66.

${ }^{21}$ T. MOMMSEN, Reden und Aufsätze, hg. von O. HIRSCHFELD, Berlin 1905 (Ndr. Hildesheim 1976), 37. Vgl. S. REBENICH, Theodor Mommsen. Eine Biographie, München $2002,121 \mathrm{ff}$.

${ }^{22} \mathrm{Vgl}$. REBENICH (wie Anm. 21), 208ff. 
strengen Methoden, die die ursprüngliche Einheit des Wissens fragmentiert hatte und die das Sollen nicht mehr aus dem Sein begründen konnte. Die großen Auseinandersetzungen um Relativität und Perspektivität der Wissenschaft kulminierten 1914 in dem „Werturteilsstreit", den Eduard Spranger mit Max Weber ausfocht. ${ }^{23}$ An die Harmonisierung historischwissenschaftlicher und lebensweltlich-normativer Erkenntnis glaubte Weber nicht. Da seiner Meinung nach die Wissenschaft durch die individuellen Wertsetzungen des Wissenschaftlers überhaupt erst konstituiert wird, vermag sie objektiv-gültige Werte nicht zu begründen. Sie kann einzig Forum eines rationalen Diskurses über divergierende Urteile sein. ${ }^{24}$ Webers Position wurde von Spranger als positivistisch abgelehnt. Vor allem konnte er sich nicht mit dessen Auffassung anfreunden, daß wertsetzende Urteile unter keinen Umständen Sache der Wissenschaft seien, sondern nur des Lebens und der Prophetie. Spranger, der Vertreter einer geisteswissenschaftlichen Pädagogik, wandte sich gegen eine Wissenschaft, die sich auf das Sammeln und Ordnen beschränke und einzig gesetzmäßige Zusammenhänge und funktionelle Abhängigkeiten beschreibe. Eine solche Wissenschaft könne, so Spranger, weder ihre Ziele noch ihre Forderungen begründen. Gegen Weber setzte Spranger seine Überzeugung, daß den Geisteswissenschaften die Aufgabe zukomme, ethische und politische Wertungen zu setzen. ${ }^{25}$

Spranger beschritt den Weg von Diltheys Hermeneutik zur Geistphilosophie: Leben, Geschichte, Werte, Kultur - dies alles sind ihm Manifestationen eines sich in Personen realisierenden Geistes. An Dilthey kritisierte er, daß dieser den häufig von ihm ausgesprochenen Satz: „Was der Mensch sei, sagt ihm nur die Geschichte" niemals ergänzt habe durch den Satz:

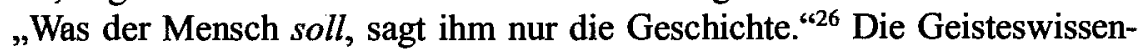
schaften sollten folglich normativen Charakter haben und der Erziehung des Menschen dienen.

${ }^{23} \mathrm{Vgl}$. hierzu H. KEUTH, Wissenschaft und Werturteilsstreit. Zu Werturteilsdiskussion und Positivismusstreit, Tübingen 1989.

${ }^{24} \mathrm{Vgl}$. A. GERMER, Wissenschaft und Leben. Max Webers Antwort auf eine Frage Friedrich Nietzsches, Göttingen 1994; O. G. OEXLE, „Wissenschaft“ und „Leben“. Historische Reflexionen über Tragweite und Grenzen moderner Wissenschaft, GWU 41, 1990, 145-161 und DERS., Geschichtswissenschaft im Zeichen des Historismus, Studien zu Problemgeschichten der Moderne, Göttingen 1996, 73-94.

${ }^{25} \mathrm{Vgl}$. K. Wuchterl, Bausteine za einer Geschichte der Philosophie des 20. Jahrhunderts, Bern u. a. 1995, 241.

${ }^{26}$ E. SPRANGER, Das Historismusproblem an der Berliner Universität seit 1900, in: DERS., Gesammelte Schriften in 11 Bänden, hg. von G. BRÄUER u. a., Heidelberg 19691980 , Bd. 5 (1960), 432. 
„Werte“ ist das zeittypische Thema des antihistoristischen Reflexes in den Geistes- und Kulturwissenschaften vor und nach dem Ersten Weltkrieg. Wir sollten nicht der Versuchung unterliegen, auf der Grundlage der späten Erinnerung von Hans Drexler, den epistemologischen Hintergrund nur in der neukantianischen Wertphilosophie zu suchen. ${ }^{27}$ Gewiß, einer der Ahnherren des Neukantianismus, Rudolf Hermann Lotze, scheint den Begriff des Wertes in den philosophischen Diskurs eingeführt zu haben, und seine Schüler Wilhelm Windelband und Heinrich Rickert stellten ihn in den Mittelpunkt ihrer Philosophie. Aber auch Friedrich Nietzsche hatte die Diskussion mit dem Schreckgespenst des Nihilismus belebt, und Max Scheler und Nicolai Hartmann entwickelten im Anschluß an Edmund Husserl eine Ethik, die dem Subjektivismus der Wertungen entgehen und eine objektive Wertphilosophie begründen sollte. $^{28}$

Doch nicht nur die Philosophie suchte nach rational begründeten und überzeitlich gültigen Wertmaßstäben für das praktische Handeln. Auch die Altertumswissenschaften wollten durch ihre wissenschaftliche Arbeit normatives Wissen bereitstellen, das in der jeweiligen Gegenwart moralisch und politisch handlungsleitend sein sollte. Schon in seinem opus magnum „Virgils epische Technik“ (1903) hatte Heinze die Rekonstruktion einer idealen Ethik der augusteischen Zeit anhand dieses Epos als „wichtige und reizvolle Aufgabe“ bezeichnet, ${ }^{29}$ und auch in seinen Reflexionen über „Die gegenwärtigen Aufgaben der römischen Literaturgeschichte“ von 1907 verwies er auf die Möglichkeit, die Geschichte der römischen Moral zu erforschen. ${ }^{30}$ Die von Nietzsche aufgeworfene Frage nach dem Verhältnis von Historie und Leben war jetzt auch in der Latinistik angekommen.

Heinze versuchte, mit seinen begriffsgeschichtlichen Arbeiten über auctoritas und fides ${ }^{31}$ die „das ganze Wesen des Römertums bestimmenden Züge“ zu erfassen. ${ }^{32}$ Die Begriffe werden nicht mehr als Reflex politischsozialer Wirklichkeit verstanden, sondern sind die in der römischen Geschichte faßbaren Emanationen von überzeitlich geltenden und geschicht-

${ }^{27}$ Vgl. etwa A. HALTENHOFF, Wertbegriff und Wertbegriffe, in: M. BRAUN, A. HALTENHOFF, F.-H. MUTSCHLER (Hgg.), Moribus antiquis res stat Romana. Römische Werte und römische Literatur im 3. und 2. Jh. v. Chr., München/Leipzig 2000, 15-29, hier $18 f$. zu H. DREXLER, Begegnungen mit der Wertethik, Göttingen 1978.

${ }^{28}$ Vgl. dazu SCHMITT (wie Anm. 1), $53 \mathrm{ff}$.

${ }^{29}$ R. HEINZE, Virgils epische Technik, Leipzig 1903, 271 ,

${ }^{30}$ HeINZE (wie Anm. 15), 174.

${ }^{31}$ R. HEINZE, Auctoritas (1925), zitiert nach DERS. (wie Anm. 6), 43-58; DERS., Fides (1929), zitiert nach DERS. (wie Anm. 6), 59-81.

${ }^{32}$ FuCHS (wie Anm. 14), 28; vgl. auch E. BURCK in der Einleitung zu HEINZE (wie Anm. 6), 10. 
lich wirksamen Ideen. ${ }^{33}$ Als „Quell“ der Macht des Augustus sah Heinze in Abgrenzung zu Mommsen keine staatsrechtlichen Konstruktionen, sondern die aus der Persönlichkeit fließende auctoritas. Sie ist in seinen Augen dafür verantwortlich, daß ,jedem römischen Bürger dauernd das Gefühl lebendig [bleibt], daß er freiwillig und zum eigenen Besten der überlegenen Persönlichkeit des princeps die Entscheidung überläßt. ${ }^{\text {“34 }}$

Heinzes Untersuchungen machten Schule. Mit Hilfe der Exzerpte für den "Thesaurus linguae Latinae" analysierte der Althistoriker Joseph Vogt nicht nur die Grundbegriffe römischer Politik und die Terminologie des römischen Imperialismus, ${ }^{35}$ sondern idealisierte den homo novus, der als „Politiker des persönlichen Wertes" durch seine virtus "die Vorrechte der Geburt" überwinde und den Idealtypus des Machtmenschen darstelle. ${ }^{36}$ Dem unbedingten römischen Willen zur Macht „eignet eine ungebrochene Selbstbejahung und der naturhafte Zwang, andere nach eigenem Willen zu lenken. “37

Im republikanischen Rom fahndete man nach zeitlosen Werten, ewigen Wahrheiten und charakteristischen Typen. Heinze rezipierte Sprangers Theorie der Lebensformen, indem er die Römer zu Machtmenschen erklärte, und er bekannte sich in seinem Beitrag „Von den Ursachen der Größe Roms“ von 1921 zwar nicht explizit, aber sehr wohl implizit zur normativen Interpretation des historischen Beispiels. ${ }^{38}$ Diese Konzeption spiegelte den wissenschaftlichen mainstream. Matthias Gelzer verkündete im selben Jahr im Vorwort seiner Caesarbiographie, „daß die Geschichtsschreibung dazu diene, aus der Vergangenheit zu lernen. ${ }^{\text {"39 }}$ Und Joseph Vogt ließ keinen Zweifel an der „vorbildlichen Bedeutung“ der römischen

${ }^{33} \mathrm{Vgl}$. etwa HEINZE (wie Anm. 6), 56 und 80.

${ }^{34} \mathrm{Vgl}$. HEINZE (wie Anm. 6), 50.

${ }^{35}$ J. VOGT, Orbis Romanus. Zur Terminologie des römischen Imperialismus, Tübingen 1929 (zitiert nach DERS., Vom Reichsgedanken der Römer, Leipzig 1942, 170 207, hier 171 Anm. 3; vgl. DERS., Orbis. Ausgewählte Schriften zur Geschichte des Altertums, Freiburg 1960, 151-171, hier 152 Anm. 3). - Zu Vogt vgl. K. CHRIST, Neue Profile der Alten Geschichte, Darmstadt 1990, 63-124 und D. KöNIGS, Joseph Vogt: Ein Althistoriker in der Weimarer Republik und im Dritten Reich, Basel/Frankfurt a. M. 1995 (mit den Rezensionen von K. CHRIST, Homo novus, Historia 44, 1995, 504-507; J. DEININGER, Gymnasium 104, 1997, 345-348; A. DEMANDT, Das historisch-politische Buch 45, 1997, 6 und W. NippEL, Gnomon 70, 1998, 373-375).

${ }^{36}$ J. VOGT, Homo novus. Ein Typus der römischen Republik, Stuttgart 1926 (vgl. DERS., Gesetz und Handlungsfreiheit in der Geschichte, Stuttgart 1955, 81-106), bes. $6 \mathrm{f}$.

${ }^{37}$ J. VOGT, Die römische Republik, Freiburg im Breisgau 1932, 45.

${ }^{38} \mathrm{Vgl}$. HEINZE (wie Anm. 6), 26f.

${ }^{39}$ Zitiert nach M. GELZER, Caesar. Der Politiker und Staatsmann, Wiesbaden ${ }^{6} 1960$, p. V. 
Geschichte „für die abendländische Menschheit. “40 Von Rom konnte man die ,instinktsichere Selbsterhaltung“ lernen, „die das Wesensfremde ablehnte und das Übernommene dem obersten Wert des Staates und der Herrschaft unterordnete. ${ }^{(4)}$

Die deutsche Latinistik und Althistorie versuchten durch das Studium einzelner Wertbegriffe dem Phänomen des Römertums näherzukommen ${ }^{42}$ und betrieben die idealisierende Rückschau und klassizistische Überhöhung des römischen Wertesystems. Manfred Fuhrmann hat bereits darauf hingewiesen, daß man versuchte, „Andacht und Bewunderung für die Größe alles dessen $\mathrm{zu}$ erzeugen, was historisch mit dem Namen Roms verbunden war."43 Dies hatte Folgen für die Begriffsgeschichte: Nach dem Ersten Weltkrieg befriedigte sie nicht mehr allein kulturhistorische und sprachwissenschaftliche, sondern verstärkt auch politische Interessen. Sie sollte zur „Erneuerung Deutschlands“ beitragen. „Von der Präzisierung römischer res publica führte eine Linie zum ,Gemeinnutz', von der Betonung römischer virtus und disciplina eine andere zur Konservierung soldatischer Tugenden, vom ,kategorischen Imperativ der Staatspflicht ${ }^{6}$ und der Einschärfung patriarchalischer Strukturen eine weitere zur bedingungslosen Unterordnung des Einzelnen unter militärische und politische Autorität. “44

Die Begriffsgeschichte, die den historistischen und erkenntnistheoretischen Relativismus der Altertumskunde des 19. Jahrhunderts bezwingen wollte, beschwor jetzt immer lauter das überzeitliche Proprium römischer virtutes. Gewiß, Richard Heinze war ein viel zu differenziert denkender Gelehrter, um sich zu platten Gleichsetzungen hinreißen zu lassen. Den römischen Machtmenschen wollte er nicht als Vorbild des neuen Deutschlands verstanden wissen..$^{45}$ Andere legten sich weniger Zurückhaltung auf. Karl Meister feierte 1930 die „sittliche[n] Werte“ der Römer, „die uns in unserer heutigen Not innerlich stärken können."46 In ebendiesem Sinne wurde auch Heinze bald gelesen, der selbst, wenn ich recht sehe, nie von Werten oder Wertbegriffen sprach. Diese Terminologie legte ihm schon wenige Jahre nach seinem Tod sein Schüler Erich Burck in den Mund, der nun darauf abhob, Heinze habe ,von den politischen und religiösen Institutionen, der gesellschaftlichen Gliederung und vom Ganzen der römischen

${ }^{40}$ VOGT (wie Anm. 37), V.

${ }^{41}$ VoGT (wie Anm. 37), 316.

${ }^{42}$ VOGT (wie Anm. 37) widmet zwei Kapitel seiner Darstellung der Auseinandersetzung des „Römertums" mit dem Hellenismus (146ff.; 315ff.).

${ }^{43}$ M. FUHRMANN, Die Romidee in der Spätantike, HZ 207, 1968, 529-561, hier 539.

${ }^{44}$ Christ (wie Anm. 14), 159.

${ }^{45}$ Vgl. Heinze (wie Anm. 6), 27.

${ }^{46}$ Zitiert nach OPPERMANN (wie Anm. 14), 1 f. 
Staatsgesinnung die einzelnen Grundwerte und virtutes des frühen Römertums deuten“ wollen. ${ }^{47}$ Burck zweifelte nicht daran, daß das Studium „der römischen politischen Leitbegriffe und ihre Konfrontierung mit den Grundanschauungen der modernen Politik und Staatsformen ungemein instruktive Aufschlüsse für eine tiefer gegründete staatsbürgerliche Erziehung und Bildung" gebe. ${ }^{48}$ Die Begriffsgeschichte hatte demnach propädeutische Funktion für die weltanschauliche Bildung.

Die latinistische Wertforschung, genauer: Wertepanegyrik der zwanziger Jahre krankte an einer fehlenden theoretischen Fundierung und versuchte die Antike als sinnstiftende historische Größe zu rehabilitieren. Zu diesem Zweck wurden politische Tugenden gepriesen, die im konservativantidemokratischen Diskurs der Weimarer Republik beheimatet waren: Autorität, Gefolgschaft und Treue. Hier finden sich Berührungspunkte der philologischen Wertforschung mit einer Althistorie, die auf der Suche nach "innerer Form“ und „geistiger" Substanz war und geschichtliches Verstehen von „Wesen" und „Geist" einforderte, irrational-messianische Erwartungen auf einen die Parteiengegensätze überwindenden Führer schürte ${ }^{49}$ und das Volkstum als „unerschöpflichen Nährboden“ des Römertums wie des Deutschtums feierte. ${ }^{50}$

\section{Der neue Geist und alte Begriffe: Begriffs- und Wertforschung im „Dritten Reich“}

Am 3. März 1939 feierte Otto Seel den „Generalstabschef und Stoßtruppführer" Gaius Julius Caesar. Der Erlanger Latinist widmete einen öffentlichen Vortrag dem Thema "Caesar und seine Gegner", lobte die „besten Eigenschaften des Römertums“, die sich "unter der jahrhundertelangen reinlichen Zucht und Formung einer von Art und Anlage tüchtigen Rasse“ in der Person des Eroberers Galliens zusammengefunden hätten, bemühte Hitlers Begeisterung für die römische Geschichte im allgemeinen und für die Gestalt Caesars im besonderen und kam schließlich auf die clementia Caesaris zu sprechen. Dabei habe es sich nicht um „eine Milde“ gehandelt, „die aus einem als verbindlich anerkannten, von beiden Seiten her einsichtigen formalen und moralischen Rechtsgrund erwachsen wäre, sondern es ist eine Auffassung herrscherlichen Wesens, um seiner selbst willen aus

${ }^{47}$ Vgl. HEINZE (wie Anm. 6), 82.

${ }^{48} \mathrm{Vgl}$. HENNZE (wie Anm. 6), 6.

${ }^{49} \mathrm{Vgl}$. S. REBENICH, Alte Geschichte zwischen Demokratie und Diktatur. Der Fall Helmut Berve, Chiron 31, 2001, 457-496.

${ }^{50}$ VoGT (wie Anm. 37), 317. 
freiem Verfügen und Ermessen als Geschenk gegeben und genommen. ${ }^{\text {" }} 1$ Diese interpretatio fascistica der sprichwörtlichen Milde des römischen Diktators liest sich wie eine Antwort auf Hellfried Dahlmanns Erörterung der clementia Caesaris, die 1934 in den „Neuen Jahrbüchern für Wissenschaft und Jugendbildung “ erschienen war und in der betont wurde, daß der "größte Römer" dem Begriff „seinen bedeutsamen Gehalt gegeben und als milder, schonender Herrscher das Vorbild geschaffen [hat], das seither für das Herrscherideal aller Zeiten maßgebend geworden ist." 52

Die beiden Zitate zeigen exemplarisch, daß die altertumswissenschaftliche Wertbegriffsforschung im „Dritten Reich“ mitnichten unter den Stichworten Anpassung und Mittäterschaft subsumiert werden kann. Das Bild, das die Untersuchung der einschlägigen, zwischen 1933 und 1945 veröffentlichten Arbeiten ergibt, ist diffus. Dies erklärt die zum Teil heftig und emotional geführte Diskussion um die Bewertung der politischen Biographien verschiedener Gelehrter. ${ }^{53}$ Doch die Beschränkung der wissenschaftshistorischen Analyse auf die nationalsozialistische Epoche greift, wie ich schon mehrfach gezeigt habe, zu kurz. ${ }^{54}$ Im Zentrum unseres Interesses muß vielmehr die Frage nach Kontinuität und Diskontinuität der Wertbegriffsforschung vom Deutschen Kaiserreich über Weimar und das "Dritte Reich" bis in die Bundesrepublik stehen. Nur auf diese Weise können die politischen, ideologischen und epistemologischen Voraussetzungen geklärt werden, die einzelne Forscher veranlaßten, sich dem nationalsozialistischen Wissenschaftssystem anzudienen, und nur so können Inhalte und Methoden der Forschung nach 1945 überzeugend beurteilt werden.

Der Lobpreis der römischen Werte und des „,Römertums“" griff häufig auf eine Begrifflichkeit zurück, die dem Arsenal der „Konservativen Revolution" der Weimarer Republik entnommen war. Die am historischen Gegenstand exemplifizierten überzeitlichen Wertvorstellungen korrespondierten mit den Erwartungen eines konservativ-völkisch orientierten Pub-

${ }^{51}$ O. SEEL, Caesar und seine Gegner. Vortrag gehalten vor der Universität Erlangen am 3. März 1939, Erlanger Universitätsreden 24, Erlangen 1939. Vgl. K. CHRIST, Zum Caesarbild der faschistischen Epoche, Berlin 1993, 22f. und DERS., Caesar. Annäherungen an einen Diktator, München 1994, $270 \mathrm{f}$.

${ }^{52}$ H. DAHLMANN, Clementia Caesaris, Neue Jahrbücher für Wissenschaft und Jugendbildung 10, 1934, 17-26 ( = H. OPPERMANN [Hg.], Römertum, Darmstadt 1962, 188-202); zitiert nach D. RASMUSSEN (Hg.), Caesar, Darmstadt 1967, 32-47, hier 47.

${ }^{53}$ Vgl. etwa A. WLosoks Nachruf für V. Pöschl, Gnomon 73, 2001, 369-378.

${ }^{54} \mathrm{Vgl}$. REBENICH (wie Anm. 49) und DERS., Nationalsozialismus und Alte Geschichte. Kontinuität und Diskontinuität in Forschung und Lehre, erscheint in: I. STARK (Hg.), Elisabeth Charlotte Welskopf und die Alte Geschichte in der DDR, Stuttgart 2005. 
likums, das den Weimarer Staat und die parlamentarische Demokratie ablehnte. Während Heinzes Rektoratsrede wie das leidenschaftliche Plädoyer eines Vernunftrepublikaners für die res publica von Weimar gelesen werden kann, nutzte Karl Meister 1930 seine Ausführungen über „Die Tugenden der Römer“, um Klage über die politische Zerrissenheit des von dem Versailler Vertrag und der wirtschaftlichen Not niedergedrückten deutschen Volkes zu führen. ${ }^{55}$ Als den Nationalsozialisten am 30. Januar 1933 die Macht übergeben wurde, hatten viele konservative Latinisten und Althistoriker längst einen antibürgerlichen, antirationalen und elitären „Wertekanon der römischen Politik und Moral der Frühzeit" rekonstruiert, ${ }^{56}$ der unverkennbare Affinitäten zur nationalsozialistischen Weltanschauung aufwies. Die Folgen für den wissenschaftlichen Diskurs über römische "Werte" hat Peter Lebrecht Schmidt am Beispiel der Klassischen Philologen Pöschl, Burck und Drexler dargestellt. ${ }^{57}$

Althistoriker standen ihren altphilologischen Kollegen nicht nach. Joseph Vogt spürte den Grundlagen des Imperium-Konzepts in einer Zeit nach, „da der Reichsgedanke seine Kraft und Hoheit wiedergewinnt, ${ }^{\text {“58 }}{ }^{\text {und klagte }}$ über die „ungeheuere Vernachlässigung der blutmäßig bedingten Grundlagen des staatlichen und kulturellen Lebens", der sich Cicero schuldig gemacht habe, weil er von einem „fast ausschließlich vom Geist her bestimmten Bild des Menschen" geprägt gewesen sei. ${ }^{59}$ Johannes Stroux untersuchte 1937 den Imperator-Begriff und feierte den Prinzipat als „die Erfüllung des Römertums“" und eine "Zeit völkischer Erneuerung“, „als Adel und Tugend der römischen Rasse dem Volk bewußt" geworden seien. ${ }^{60}$ Hans Volkmann forderte, „aus dem Wesen des Römertums, also aus

${ }^{35}$ Zitiert nach OPPERMANN (wie Anm. 14), $13 \mathrm{ff}$.

${ }^{56}$ E. BURCK in: HEINZE (wie Anm. 6), 6.

${ }^{57}$ Vgl. SCHMIDT (wie Anm. 3).

${ }^{58}$ J. VOGT, Der Reichsgedanke in der römischen Kaiserzeit, in: DERS., Vom Reichsgedanken der Römer, Leipzig 1942, 5-34, hier 5.

${ }^{59}$ J. VOGT, Ciceros Glaube an Rom, Stuttgart 1935 (zitiert nach dem unveränderten Nachdruck Darmstadt 1963), 85f. Dort heißt es zudem: ,Wir müssen uns ... wundern, daß ein Politiker, der so unablässig die Größe der Vergangenheit feierte, so klar den Niedergang der Gegenwart sah und so sorgenvoll in die Zukunft blickte, die Bedeutung der vitalen Energien im Völkerleben so unzureichend gewürdigt hat. Die fortgesetzte minderwertige Mischung der Bürgerschaft vor allem in Rom, die zahlenmäßige Schwächung der regierenden Schicht, der Ruin des italischen Bauerntums, alle diese notorischen Schäden haben ihn nicht erschüttert.“

${ }^{60}$ J. STRoux, Imperator, Die Antike 13, 1937, 197-212, hier 198. Der augusteische Prinzipat wurde zum Vorläufer des wiedererstarkten „Dritten Reichs“". „Gerade dies auch im Volke selbst erweckte Gefühl, daß diese Zeit alle Anlagen der Nation, alle vorausbestimmte Größe, alle durch die Taten der Ahnen schon erstrittenen Vorstufen des nationalen Ruhmes zur Vollendung bringe, daß erst diese Gegenwart offenbare, was 
blutgebundenen Kräften die Eigenart des Augustus in seinem politischen Handeln und seinem Erfolge zu erklären," und machte den mos maiorum zum „Grundzug des augusteischen Prinzipats"; es bedurfte, so Volkmann, des „Wiedererwachen[s] starker völkischer Kräfte“, um zu erkennen, daß Augustus ,in echt römischem Empfinden den einzigen dem Römertum entsprechenden Weg“" gegangen sei und ein neues Reich ,auf dem Fundament alter, zeitweise verschütteter sittlicher und geistiger Kräfte" gebaut habe. ${ }^{61}$ Franz Altheim glaubte schließlich, die römische fides mit der germanischen Treuverpflichtung vergleichen zu können, und warf die Frage auf, ob ein gemeinsames „Erbe aus indogermanischer Zeit" vorliege. ${ }^{62}$

Den wissenschaftlichen Tiefpunkt erreichte die Wertforschung, als sich Fachvertreter anschickten, einzelne Begriffe mit der Rassenlehre in Beziehung zu setzen. Friedrich Klose, der 1933 an der Universität Breslau mit einer Arbeit über die Bedeutung von honos und honestus promoviert worden war, ${ }^{63}$ wollte 1938 an prominenter Stelle vermeintliche Gegensätze zwischen deutschen und römischen Wertbegriffen mit Hilfe der Rassenseelenkunde erklären. ${ }^{64}$ Wie sehr sich die deutsche Altertumskunde mit solchen Beiträgen isolierte, zeigt ein Vergleich mit zeitgenössischen angelsächsischen Untersuchungen zu den virtutes des römischen Kaisers, deren öffentlichkeitswirksame Darstellung als "means and modes“ imperialer Propaganda verstanden wurden, die die herausragende Position des princeps legitimieren und stabilisieren sollten. ${ }^{65}$

Doch jenseits einer politisierten oder nazifizierten Wertforschung gab es in Deutschland eine Fülle von Spezialstudien, die in der Tradition der frühen begriffsgeschichtlichen Untersuchungen das Material zusammenstellten und mehr oder weniger vollständig grammatikalische, sprachliche und semantische Probleme diskutierten. Die meist nüchternen, oft ein

Roms Macht und Volk für die Menschheit bedeute, trug und formte den neuen Glauben der Römer an sich selbst und den Augusteischen Geist" (200).

${ }^{61}$ H. VolKMANN, Mos maiorum als Grundzug des augusteischen Prinzipats, in: $H$. Berve (Hg.), Das neue Bild der Antike, Bd. 2, Leipzig 1942, 246-264, hier 246ff. Zu Volkmann vgl. CHRIST (wie Anm. 14), $255 f$.

${ }^{62}$ F. AlTHEIM, Italien und Rom, Bd. 2, Amsterdam/Leipzig 1941,194-200, hier 200. $\mathrm{Zu}$ Altheim vgl. CHRIST (wie Anm. 14), 246ff. und V. LOSEMANN, Nationalsozialismus und Antike. Studien zur Entwicklung des Faches Alte Geschichte 1933-1945, Hamburg $1977,123 \mathrm{ff}$.

${ }^{63}$ F. KLOSE, Die Bedeutung von honos und honestus, Diss. phil. Breslau 1933.

${ }^{64}$ F. KLOSE, Altrömische Wertbegriffe (honos und dignitas), Neue Jahrbücher für Antike und deutsche Dichtung 1, 1938, 268-278.

${ }^{65}$ Vgl. M. P. CHARLESwORTH, The Virtues of a Roman Emperor. Propaganda and the Creation of Belief, Proceedings of the British Academy, London 1937, 105-133, hier 127 und DERS., Pietas and Victoria: The Emperor and the Citizen, JRS 33, 1943, 1-10. 
wenig langweiligen Untersuchungen sichteten das für einen Begriff einschlägige Material, fragten nach Bedeutungswandel und -konstanz und analysierten - so würden wir heute sagen - verschiedene Normen der politischen und sozialen Kommunikation in der römischen Republik und im Prinzipat. Begriffsgeschichtliche Untersuchungen waren - nicht nur in Breslau $^{66}$ - ein beliebtes Promotionsthema. ${ }^{67}$ Die Qualifikationsarbeiten orientierten sich fast durchweg an den überkommenen Standards der Disziplin, die im 19. Jahrhundert entwickelt worden waren. ${ }^{68}$ Die Phalanx der jungen Wissenschaftler überließ weltanschauliche Experimente ihren Lehrern. Saubere Quellenkritik führte, so wußten sie, wesentlich sicherer zum Erfolg als nationalsozialistische Bekenntnisschriften.

Dennoch sollte man sich davor hüten, schon hinter dem Titel einer Schrift - etwa über libertas - eine mögliche regimekritische Haltung zu vermuten. ${ }^{69}$ Hier heißt es, genau hinzusehen. So enthält die von Max Pohlenz in Göttingen betreute Dissertation von Rudolf Stark über res publica nicht nur Untersuchungen zur Bedeutungsgeschichte des Wortes, sondern auch ein Plädoyer für einen Rechtsstaat, in dem bürgerliche civilitas geschützt wird. Zu Cic. rep. 3,45 wird ausgeführt: „In der Demokratie aber, in der die libertas ihren eigentlichen Sitz hat, führt die Radikalisienung zur Aufhebung des iuris consensus, und die Freiheit schlägt in die Tyrannei der vielköpfigen Masse um. "70 In einer bei Wilhelm Weber in Berlin angefertigten Dissertation hingegen, die sich den Beziehungen zwischen römischer Herrscheridee und päpstlicher Autorität widmete, findet sich die Theorie, daß die römischen Bischöfe das "letztlich nordische Ideal“ der auctoritas ,,in die christliche Gedankenwelt" übersetzt hätten; ,seitdem die nordischen Italiker durch die Kraft ihres Blutes und Gestaltens die Grund-

${ }^{66} \mathrm{Vgl}$. die Zusammenstellung bei CLASSEN (wie Anm. 13), 40 Anm. 3.

${ }^{67} \mathrm{Vgl}$. die Übersichten bei E. BuRCK in: HeINZE (wie Anm. 6), 1. Aufl. 1938, 283f, ClassEN (wie Anm. 13), 40 Anm. 4; Fuchs (wie Anm. 14) und OPPERMANN (wie Anm. 14), IX-XI.

${ }^{68} \mathrm{Vgl}$. auch LOSEMANN (wie Anm. 62), 84f. sowie REBENICH, Nationalsozialismus und Alte Geschichte (wie Anm. 54).

${ }^{69}$ So Classen (wie Anm. 13), 40; vgl. auch Thome (wie Anm. 7), Bd. 1, 10 Anm. 9 zur Dissertation von H. KLOESEL, Libertas, Breslau 1935 (OPPERMANN [wie Anm. 14], 120-172), die den primär persönlichkeitsbezogenen, aristokratischen Zug der römischen libertas betont. Vgl, jedoch J. BLEICKEN, Staatliche Ordnung und Freiheit in der römischen Republik, Kallmünz 1972, 13 Anm. 11, der za Recht darauf hinweist, daß die Studie einige ,zum geringen Teil durch den Zeitgeist bedingte Fehlurteile“ aufweise.

${ }^{70}$ R. STARK, Res publica, Diss, phil. Göttingen 1937, 45 (= OPPERMANN [wie Anm. 14], 42-110, hier 91). 
lagen der ewigen Stadt gelegt haben, lebt in Rom die auctoritas eines Princeps, des adligen Führers, des Königs oder später des Kaisers. ${ }^{671}$

Aber nicht nur Doktoranden, auch ambitionierte junge Altertumsforscher wandten sich bereits seit Mitte der zwanziger Jahre der Begriffsgeschichte zu: ${ }^{72}$ Friedrich Zucker schrieb 1928 über conscientia, ${ }^{73}$ Hellfried Dahlmann 1934 über clementia Caesaris, ${ }^{74}$ Ulrich Knoche im selben Jahr über gloria und magnitudo animi, ${ }^{75}$ und Hans Ulrich Instinsky untersuchte aeternitas und consensus universorum. ${ }^{76}$ Eine deutliche Vorliebe für die Republik und den frühen Prinzipat fällt auf. In diesen beiden Epochen glaubte man die originären altrömischen Werte aufspüren zu können. Folglich blieb die Spätantike häufig ausgeklammert. ${ }^{77}$ Auch wenn in diesen gediegenen Abhandlungen nicht das politische Lied auf Volk, Führer und Vaterland gesungen wurde, so folgten die Verfasser meist der zeittypischen Relativierung juristischer und sozialer Fragen und der Akzentuierung irrationaler Phänomene. Der politisch gänzlich unverdächtige Hans Ulrich

${ }^{71}$ U. GMELIN, Römische Herrscheridee und päpstliche Autorität, Stuttgart 1937, IIIf. (vgl. U. GMELIN, Auctoritas, römischer Princeps und päpstlicher Primat, Diss. phil. Berlin 1936).

${ }^{72} \mathrm{Vgl}$. auch die in Anm. 67 genannten Literaturüberblicke.

${ }^{73}$ F. ZUCKER, Syneidesis - conscientia. Ein Versuch zur Geschichte des sittlichen Bewußtseins im griechischen und im griechisch-römischen Altertum, Jena 1928.

${ }^{74}$ Vgl. Anm. 52.

${ }^{75}$ U. KNOCHE, Der römische Ruhmesgedanke, Philologus 89, 1934, 102-124 (vgl. = DERS., Vom Selbstverständnis der Römer, Gymnasium Beiheft 2, Heidelberg 1962, 13 30; OPPERMANN [wie Anm. 14], 420-445); DERS., Magnitudo animi. Untersuchungen zur Entstehung und Entwicklung eines römischen Wertgedankens, Philologus Suppl. 37, Leipzig 1935 (= DERS., Vom Selbstverständnis der Römer, 31-97).

${ }^{76}$ H. U. INSTINSKY, Kaiser und Ewigkeit, Hermes 77, 1942, 313-355 und DERS., Consensus Universorum, Hermes 75, 1940, 265-278 (= OPPERMANN [wie Anm. 14], 209228).

${ }^{77}$ Allerdings sind begriffsgeschichtliche Untersuchungen, die sich auf das frühe Christentum und die Spätantike erstrecken, ein zentraler Bestandteil des von Franz Joseph Dölger angeregten „Reallexikons für Antike und Christentum" (RAC), das zwischen 1935 und 1941 vorbereitet wurde, aber erst nach dem Zweiten Weltkrieg realisiert werden konnte; zur Geschichte des Unternehmens vgl. das (nicht paginierte) Vorwort von T. KLAUSER in RAC 1 (1950) sowie allg. DERS., Franz Josef Dölger 1879 1940. Sein Leben und sein Forschungsprogramm „Antike und Christentum", JbAC Ergänzungsband 7, Münster 1980. Die Ausführungen zur „vorchristlichen“ Bedeutung einschlägiger Termini rekurrieren meist unkritisch auf die ältere Wertbegriffsforschung, vgl. z. B. H. WAGENVOORT, G. TELlENBACH, Art. „Auctoritas", in: RAC 1 (1950), $902-$ 909; H. WINKLER, Art. „Clementia“, in: RAC 2 (1957), 206-231; W. DürIG, Art. „Dignitas", in: RAC 3 (1957), 1024-1035; C. BECKER, Art. „Fides", in: RAC 7 (1969), 801-839 und A. J. VERMEULEN, Art. „Gloria“, in: RAC 11 (1981), 195-225. 
Instinsky ${ }^{78}$ bekundete etwa, entscheidend für das Verständnis des consensus sei nicht seine rechtliche und soziale, sondern vielmehr seine emotionale und religiöse Bedeutung: „In ihm kann sich das Bekenntnis der Gefolgschaft zum Führer, das Bekenntnis der Stände, des Volkes, der Heere, der Provinzen zum Princeps äußern; nicht aber, um eine rechtliche Bindung herzustellen oder die soziale Verbindung auszudrücken: er begründet die Sphäre, in der neben der realen Macht die irrationalen Kräfte der Treue, des Dankes und der religiös gesteigerten Verehrung für den Herrscher sichtbar werden.“79 Und Leopold Wenger meinte, auctoritas habe „immer einen geheimnisvollen Inhalt, ein Etwas, das juristischer Formulierung heute widerstrebt. “80

Ein Vergleich dieser Ausführungen mit den „Prinzipien des römischen Rechts “ des Rechtshistorikers Fritz Schulz läßt die Charakteristika der deutschen Wertbegriffsforschung in dieser Epoche deutlich hervortreten. Schulz hatte schon 1934 das römische Recht als Produkt der römischen Gesellschaft dargestellt, unter auctoritas „das soziale Ansehen einer Person oder Institution“ verstanden und versucht, die „besonders geartete Autorität“ des römischen Prinzeps mit Hilfe der von Max Weber beschriebenen Kategorie „der charismatischen Autorität" zu fassen. ${ }^{81}$ Das innovative Potential seines kulturgeschichtlichen Ansatzes konnte in Deutschland nicht wirken: Fritz Schulz wurde als "Jude" von den Nationalsozialisten aus der akademischen Gemeinschaft vertrieben und emigrierte bald nach den Novemberpogromen von 1938 nach England. Eine englische Übersetzung seines Buches beeinflußte die angelsächsische Forschung nachhaltig.

Auch die Forschungen Hermann Strasburgers waren im „Dritten Reich“ nicht mehrheitsfähig: Matthias Gelzers Schüler hatte nicht nur in seiner Dissertation über concordia ordinum den „Realpolitiker“ Cicero und dessen Versuche, die überkommene Ordnung der Republik zu wahren, gegen Theodor Mommsens Polemik verteidigt, sondern in seinem OptimatesArtikel in Pauly-Wissowas Realenzyklopädie Zweifel an der gängigen

${ }^{78}$ Vgl. S. REBENICH, Alfred Heuß: Ansichten seines Lebenswerkes. Mit einem Anhang: Alfred Heuß im Dritten Reich, HZ 271, 2000, 661-673, hier 673 mit Anm. 41.

${ }^{79}$ INSTINSKY, Consensus (wie Anm. 76), 276 (225).

${ }^{80}$ Vgl. L. WENGER in: Studi di storia e diritto in onore di Enrico Besta, Bd. 1, Mailand $1938,152 \mathrm{f}$.

${ }^{81}$ F. SCHULz, Prinzipien des römischen Rechts, München 1934 (Ndr. Berlin 2003), 112 und 123ff. Schulz' Darstellung wurde von M. GELZER in: Gnomon 11, 1935, 1-6 (= DERS., Kleine Schriften, Bd. 1, Wiesbaden 1962, 284-289) besprochen. Zu Schulz vgl. E. WOLF, in: J. BEATSON, R. ZIMMERMANN (Hgg.), Jurists Uprooted. German-speaking Emigré Lawyers in Twentieth-Century Britain, Oxford 2004, 105-203. 
These von dem notwendigen Untergang der res publica geäußert. ${ }^{82}$ Solche Stimmen verhallten damals ungehört. Selbst die Begriffsgeschichte hatte ihren Beitrag zur vermeintlich wissenschaftlichen Legitimation autokratischer Herrschaft zu leisten.

In Deutschland wurde die begriffsgeschichtliche Methode, die für die Arbeit am "Thesaurus" konstituiert worden war, nicht fortentwickelt, das fächerübergreifende Gespräch (etwa mit Gerhard Kittel, der das „Theologische Wörterbuch zum Neuen Testament", dessen erster Band 1933 erschien, begründet hatte) nicht gepflegt und über das epistemologische Fundament einer antihistoristischen Begriffsgeschichte nicht debattiert.

\section{Alter Wein in alten Schläuchen: Die Theorieabstinenz nach 1945}

„Die Frage drängt sich auf, ob im Laufe der Zeit nicht überhaupt - mit "Gesetzmäßigkeit, mit innerer Notwendigkeit - die Begriffe verbraucht, abgenützt werden, und ob nicht für die Werte und auch für die Institutionen selbst das Gleiche gilt, vielmehr: ob sich dies nicht in den Termini nur spiegelt und für den Philologen dort besonders leicht greifbar wird. Was könnte mehr entmutigen als das Ansehen, das in der Kaiserzeit der Begriff libertas erhielt?“83 Carl Becker bestätigt mit seiner Universitätsrede von 1967 exemplarisch die Kontinuität einer traditionellen Wertforschung, die auf begriffsgeschichtliche Untersuchungen rekurrierte. Dabei ignorierte er wie die meisten seiner Kollegen ${ }^{84}$ geflissentlich, daß die einst historistische Begriffsgeschichte, die sich seit dem Beginn des 20. Jahrhunderts dem Sog des Relativismus zu entziehen versucht hatte, einen Prozeß der Ideologisierung durchlaufen hatte, durch den ihr wissenschaftlicher Anspruch in Frage gestellt worden war. ${ }^{85}$

Natürlich war diese Forschungsrichtung schon dadurch diskreditiert, daß sie in der Bundesrepublik vor allem von Hans Drexler und Hans Oppermann, die mit und durch den Nationalsozialismus Karriere gemacht hatten, vertreten wurde. Während Oppermann die römischen Werte erst nach dem

${ }^{82}$ H. STRasburger, Concordia Ordinum. Eine Untersuchung zur Politik Ciceros, Diss. Frankfurt 1931 (= DERS., Studien zur Alten Geschichte, Bd. 1, Hildesheim/New York 1982, 1-82); DERS., Art. „Optimates“, in: RE 18.1 (1939), 773-798 (= DERS., Studien, Bd. 1, 329-341); vgl. "C. MEIER, Gedächtnisrede auf Hermann Strasburger, Chiron 16, 1986, 171-197, zitiert nach H. STRASBURGER, Studien zur Alten Geschichte, Bd. 23, Hildesheim/New York 1990, 503-529, hier 509f.

${ }^{83}$ C. BECKER, Wertbegriffe im antiken Rom - ihre Geltung und ihr Absinken zum Schlagwort, Münchner Universitätsreden, Neue Folge H. 44, 1967, 12.

${ }^{84} \mathrm{Vgl}$. auch Joseph Vogts Untersuchung des Begriffs barbarus in: J. VoGT, Kulturwelt und Barbaren. Zum Menschheitsbild der spätantiken Gesellschaft, Mainz 1967.

${ }^{85}$ Zur Entwicklung der Begriffsgeschichte vgl. auch MEIER (wie Anm. 19), 788-808. 
Ende des Zweiten Weltkrieges entdeckte, setzte Drexler seine Forschungen fort. Er konstruierte im Nachdruck ${ }^{86}$ seiner Rektoratsrede von 1943 über dignitas den politik- und ideologiefreien Raum der reinen Wissenschaft, den es an der Universität gegen den nationalsozialistischen Mißbrauch zu verteidigen gegolten habe. Mit kollegialem Plazet stilisierte er sich zum Widerstandskämpfer. In seinem Beitrag über das bellum iustum aus dem Jahr 1959 bemerkte Drexler, der Sieg im Krieg sei „im letzten Grund ein Sieg des Glaubens, die eigentlich vernichtende Niederlage die des Unglaubens - wir selbst sind geschichtliche Zeugen dieser Tatsache -, und sie ist dann am vernichtendsten, wenn der Sieger versteht, in dem Besiegten auch noch die Möglichkeit des Glaubens zu zerstören. ${ }^{\text {(87 }}$ Zwei Jahre später, 1961, sah sich Drexler in seinen Vorbehalten gegenüber den demokratischen Parteien der Bundesrepublik durch Sallust bestätigt. ${ }^{88}$

Zur wissenschaftlichen Bewertung dieser Arbeiten haben Christian Meier, Aloys Winterling und Cornelia Wegeler alles Erforderliche gesagt. ${ }^{89}$ Die Wissenschaftliche Buchgesellschaft in Darmstadt hat Drexler wahrlich keinen Gefallen getan, vier Jahre nach seinem Tod diese Aufsätze wieder nachzudrucken. ${ }^{90}$ Wie viele andere verweigerten Oppermann ${ }^{91}$ und Drexler jegliches Nachdenken über ihre Position und ihre Verantwortung in der Universität und darüber hinaus in der akademischen res publica während der Zeit des Nationalsozialismus. ${ }^{92}$ Einer ,glaubwürdige[n] und reflexive[n]

${ }^{86}$ R. KLEIN (Hg.), Das Staatsdenken der Römer, Darmstadt 1966 (Ndr. 1980), 231254, hier 231 Anm. *.

${ }^{87}$ H. DREXLER, lustum bellum, RhM 102, 1959, 97-140, zitiert nach DERS., Politische Wertbegriffe der Römer, Darmstadt 1988, 188-226, hier 199.

${ }^{88}$ H. DREXLER, Nobilitas, Romanitas 3, 1961, 158-188, zitiert nach DERS., Politische Wertbegriffe (wie Anm. 87), 73-99, hier 99: „Wir hingegen sind nicht nur an die Existenz von Parteien gewöhnt, sondern wir halten sie zu dem Grade für rechtmäßig, daß - um ein sehr bezeichnendes Faktum anzuführen - Spenden zu ihren Gunsten ebenso wie die Kirchensteuer oder Beiträge zu wohltätigen Zwecken von der Staatssteuer abgesetzt werden können. Aber ich halte ein, um mich nicht mit den Worten Sallusts (lug. 4,9) zur Ordnung rufen zu müssen: verum ego liberius altiusque processi, dum me civitatis morum piget taedetque.“

${ }^{89}$ Vgl. die Besprechungen von C. MEIER, HZ 206, 1968, 467f. und A. WiNTERLING, Gymnasium 97, 1990, 87-89 sowie C. WEGELER, „... wir sagen ab der internationalen Gelehrtenrepublik." Altertumswissenschaft und Nationalsozialismus. Das Göttinger Institut für Altertumskunde 1921-1962, Wien u. a. 1996, 244ff.

${ }^{90} \mathrm{Vgl}$. Anm. 87.

${ }^{91}$ Zu Hans Oppermann vgl. J. MALITZ, Römertum im „Dritten Reich“: Hans Oppermann, in: P. KNEISSL, V. LoSEMANN (Hgg.), Imperium Romanum. Studien zu Geschichte und Rezeption. FS Karl Christ, Stuttgart 1998, 519-543.

${ }^{92}$ Vgl. hierzu auch O. G. OEXLE, ,Zusammenarbeit mit Baal“. Über die Mentalitäten deutscher Geisteswissenschaftler 1933 - und nach 1945, Historische Anthropologie 8, 2000, 1-27, hier 22ff. 
Lernfähigkeit ${ }^{493}$ stand wohl auch entgegen, daß für beide das Ende des „Dritten Reiches“ gleichbedeutend war mit dem Ende ihrer universitären Karrieren.

Allein, für die Bewertung der latinistischen Wertforschung der Bundesrepublik scheint dieser biographische Aspekt weniger bedeutsam als das persistierende Theoriedefizit einer konservativen Disziplin, die inhaltlich und methodisch an die antihistoristische Begriffsforschung anknüpfte, ohne sich über deren wissenschaftsgeschichtliche und epistemologische Voraussetzungen Klarheit zu verschaffen. Auf diese Weise haben Erich Burck, Karl Büchner, Hans Drexler, Ulrich Knoche, Viktor Pöschl, Otto Seel und andere einen ahistoristischen Wertbegriff fortgeschrieben und sich trotz der existentiellen Erfahrung zweier Kriege und totalitärer Systeme der Erkenntnis verschlossen, daß Werte und andere Urteile standortgebunden und folglich relativ sind. Weder Max Weber wurde rezipiert, der verdeutlicht hatte, daß Werte individuelle Setzungen waren, ${ }^{94}$ noch Carl Schmitt gelesen, der die "Tyrannei der Werte" einer scharfen und schlüssigen Kritik unterzog und darauf beharrte, daß nicht „Werte“, sondern das Gesetz die Grundlage des säkularen Rechtsstaates bilden müsse. ${ }^{95}$

Nach wie vor war man davon überzeugt, daß lateinische Wörter überzeitliche Ideen verkörperten. Pöschl ist nicht nur im Jahr 1940 auf der Suche nach dem idealen römischen Staat und einer zeitlosen römischen Moral, ${ }^{96}$ sondern auch noch in den 80 er Jahren des 20. Jahrhunderts. ${ }^{97} \mathrm{Er}$

${ }^{93}$ H.-U. WEHLER, Nationalsozialismus und Historiker, in: W. SCHULZE, O. G. OEXLE (Hgg.), Deutsche Historiker im Nationalsozialismus, Frankfurt a. M. 1999, 306-339, hier 328.

${ }^{94} \mathrm{Vgl}$. etwa M. WEBER, Gesammelte Aufsätze zur Wissenschaftslehre, Tübingen ${ }^{7} 1988$, 146ff;; 489ff. und 582ff. sowie allgemein A. WITTKAU, Historismus. Zur Geschichte des Begriffs und des Problems, Göttingen ${ }^{2} 1994,131 \mathrm{ff}$.

${ }^{95} \mathrm{Vgl}$. Anm. 1.

${ }^{96} \mathrm{~V}$, PöSCHL, Grundwerte römischer Staatsgesinnung in den Geschichtswerken des Sallust, Berlin 1940, 1f: Vgl. ebd. 110: „Die Prinzipien der römischen Politik, soweit sie im Werke Sallusts in Erscheinung treten, gruppieren sich um das Virtusideal und das Ideal der maßvollen und gerechten Herrschaft ... Das Virtusideal ist notwendiger Ausdruck der gewaltigen Arbeitsleistung und unerhörten Kraftanstrengung, die die militärische Verteidigung ebenso wie die politische Leitung eines Reiches wie des römischen erfordert. Das Ideal der mäßigen und gerechten Herrschaft ist gleichfalls eine Forderung, die sich aus den Führungsaufgaben ergibt, die Rom zu erfüllen hat"; ebd. 113: „Der Glaube an die Richtigkeit der Prinzipien altrömischer Politik und Lebensauffassung steht aufrecht über allem Zerfall."

${ }^{97}$ V. PöSCHL, Politische Wertbegriffe in Rom, A\&A 26, 1980, 1-17 (= DERS., Lebendige Vergangenheit. Abhandlungen und Aufsätze zur römischen Literatur und ihrem Weiterwirken, Kleine Schriften, Bd. 3, hg. von W.-L. LIEBERMANN, Heidelberg 1995, 189-208), hier etwa 16 (204): „Das Geheimnis der politischen Begabung der Römer und, wie ich glaube, der politischen Begabung überhaupt, besteht also nicht in erster Linie im 
und die anderen einschlägig ausgewiesenen Philologen geben weder sich noch dem Leser Rechenschaft, warum bestimmte Begriffe im Gegensatz zu anderen Wertbegriffe sein sollen, ${ }^{98}$ und ignorieren die Tatsache, daß begriffsgeschichtlich erhobene Befunde zum Wandel oder zur Konstanz von Semantik und Pragmatik politisch-kultureller Deutungskategorien keine vorschnellen und weitreichenden historischen Interpretationen erlauben. Die latinistische Begriffsgeschichte pflegte auch noch lange nach 1945 einen traditionell ideengeschichtlichen Zugang und verstand Begriffe als isolierbare Untersuchungsgegenstände, die Ideen repräsentieren. Die Wechselwirkungen zwischen Begriffen und sozialen, politischen und ökonomischen Faktoren wurden, wenn überhaupt, nur am Rande wahrgenommen.

\section{Neue Wege: Alte Geschichte und Begriffsgeschichte}

Die klassisch-philologische Wertforschung hat über Jahrzehnte hinweg neuere Ansätze, die in den Nachbarwissenschaften entwickelt wurden, nicht zur Kenntnis genommen und damit ihre disziplinäre Isolierung selbst gefördert. Erst in den achtziger Jahren hat Carl Joachim Classen die althistorische und die archäologische Forschung berücksichtigt, ${ }^{99}$ und sein Schüler Meinolf Vielberg hat, soweit ich sehe, als erster versucht, seine erkenntnisleitenden Begriffe „Pflichten, Werte und Ideale“ inhaltlich zu klären. ${ }^{100}$ Dennoch fehlt es grundsätzlich an interdisziplinärer Sensibilität und

Machtmenschentum, sondern in der Bewahrung sozialer Bindungen, in der Konservierung von Zügen einer kollektiven Moral auch noch in entwickelteren Lebensverhältnissen." Vgl. DERS., Der Begriff der Würde im antiken Rom und später, in: SHAW 1989, 3 (= DERS., Lebendige Vergangenheit, 209-274), hier 25 (227): „Aber mehr noch prägt römische Willenshaltung, männliche Selbstbeherrschung und Zurückdrängung des Emotionalen den römischen Begriff der Würde." Vgl. ferner DERS., Art. „Würde I.“", in: Geschichtliche Grundbegriffe 7, Stuttgart 1992, 637-645, hier 639: „Wer auf dignitas Anspruch erhebt, muß Selbstdisziplin üben. Er muß das Animalische und Emotionale in sich selbst bezwingen. Dies vor allem macht den Begriff, Würde' zu einem Element des römischen Selbstbewußtseins und des römischen Überlegenheitsgefuihles, einem Wesensmerkmal römischer Haltung und römischen Stils.“

${ }^{98} \mathrm{Vgl.} \mathrm{HaltenHOFF}$ (wie Anm. 27), 17 Anm. 7.

${ }^{99}$ CLASSEN (wie Anm. 13); vgl. auch DERS., Virtutes Romanorum. Römische Tradition und griechischer Einfluß, Gymnasium 95, 1988, 289-302 (- DERS., Zur Literatur und Gesellschaft der Römer, Stuttgart 1998, 243-254); DERS., Virtutes imperatoriae, Arctos 25, 1991, 17-39 (= DERS., Zur Literatur und Gesellschaft, 255-271) und DERS., Römische Wertbegriffe im Alltag der Römer, AAntHung 40, 2000, 73-86.

${ }^{100}$ M. VIELBERG, Pflichten, Werte, Ideale. Eine Untersuchung zu den Wertvorstellungen des Tacitus, Stuttgart 1987, 16ff. 
theoretischer Reflexion. Die erratische Studie von Hans Drexler „Begegnungen mit der Wertethik" ist in dieser Beziehung nicht einschlägig. ${ }^{101}$

Die Alte Geschichte hingegen öffnete sich seit den siebziger Jahren einer Begriffs- und Diskursgeschichte, die durch den Mediävisten Otto Brunner begründet worden war und der Reinhart Koselleck den Weg wies. Der Bielefelder Historiker machte unmißverständlich deutlich, daß sich begriffsgeschichtliche Studien ,ganz spezifisch gegen eine abstrakte Ideengeschichte" richten und "den konkreten Sprachgebrauch im sozialen, politischen oder rechtlichen Leben“ zu untersuchen haben. „Dabei werden die konkreten Erfahrungen und Erwartungen ausgemessen, wie sie sich in der sprachlichen Erfassung der jeweiligen rechtlichen, sozialen oder politischen Bereiche wiederfinden lassen. Dazu bedarf es immer zentraler Begriffe, die ihrerseits mehr oder minder hohen Abstraktionsgrad enthalten. Die Begriffsgeschichte liefert gleichsam die Gelenke, die zwischen der textund sprachgebundenen Quellenebene und der politischen und sozialen Wirklichkeit eine Verbindung herstellen." ${ }^{\text {"102 }}$

An dem epochalen Wörterbuch zur politisch-sozialen Sprache, an den "Geschichtlichen Grundbegriffen" (1972-1992) ${ }^{103}$ haben die Althistoriker Jochen Bleicken und Christian Meier mitgearbeitet und die Erträge der begriffsgeschichtlichen Theoriediskussion für die Altertumswissenschaften fruchtbar gemacht. Sie folgten Kosellecks Verständnis vom „Begriff“ und seiner Rekonstruktion der Interdependenz von Begriffs- und Sozialgeschichte. Begriffe sind „Konzentrate vieler Bedeutungsgehalte“; ein Begriff ist demnach vieldeutig und „bündelt die Vielfalt geschichtlicher Erfahrung und eine Summe von theoretischen und praktischen Sachbezügen in einem Zusammenhang, der als solcher nur durch den Begriff gegeben ist und wirklich erfahrbar wird." 104 Die Begriffsgeschichte hat deshalb zunächst den jeweiligen Wortgebrauch und dessen historische Kontexte zu klären. In einem zweiten Schritt sind dann diachrone Entwicklungen aufzuzeigen, und es muß gefragt werden, in welchem Verhältnis Konstanz oder Wandel der Bedeutungen zu außersprachlichen Faktoren stehen. Kosellecks Vorhaben interpretiert folglich „die Geschichte durch

${ }^{101} \mathrm{Vgl}$. Anm. 27 sowie HaltenHoff (wie Anm. 27), 19 mit Anm. 14.

${ }^{102}$ R. KOSELLECK, Begriffsgeschichtliche Probleme der Verfassungsgeschichtsschreibung, in: H. QUARITSCH (Hg.), Gegenstand und Begriffe der Verfassungsgeschichtsschreibung, Berlin 1983, 7-46, 45. Vgl. DERS., Vergangene Zukunft. Zur Semantik geschichtlicher Zeiten, Frankfurt 1989, bes. 107ff. und $211 \mathrm{ff}$.

${ }^{103}$ O. BUNNER, W. CONZE, R. KOSELLECK (Hgg.), Geschichtliche Grundbegriffe. Historisches Lexikon zur politisch-sozialen Sprache in Deutschland, 8 Bde., Stuttgart 1972-1997.

${ }^{104}$ R. KosELLECK, Einleitung, in: Geschichtliche Grundbegriffe (wie Anm. 103), Bd. 1, Stuttgart 1972, XXIIf. 
ihre jeweiligen Begriffe so, wie es die Begriffe geschichtlich versteht: die Begriffsgeschichte hat die Konvergenz von Begriff und Geschichte zum Thema." 105

Christian Meier hat den Wandel der politisch-sozialen Begriffswelt im 5. Jh. v. Chr, untersucht ${ }^{106}$ und im Anschluß an Franz Wieacker den mos maiorum als Bestand von kollektiven Leitvorstellungen der Moral des öffentlichen Handelns interpretiert. ${ }^{107}$ Jochen Bleicken hat die neue Begriffsgeschichte für die Rekonstruktion der ,staatlichen Ordnung und Freiheit in der römischen Republik“ erfolgreich eingesetzt und die Hypothese dekonstruiert, in Rom habe es eine überzeitliche Idee der Freiheit gegeben, „die als in sich selbst ruhendes Theorem das politische Handeln der Menschen bestimmt hätte“. Libertas war folglich „nicht Gegenstand theoretischer Reflexionen, sondern erwuchs ausschließlich aus der politischen Aktion bestimmter historischer Situationen und blieb ihrem Inhalt nach stets diesen Situationen verhaftet." ${ }^{108}$ Eine Vielzahl althistorischer Untersuchungen hat die Abhängigkeit der virtutes Romanorum von der sozialen und politischen Realität und damit die historische Bedingtheit von Werten und Normen nachgewiesen ${ }^{109}$ und zugleich einen gangbaren Weg

${ }^{105}$ KoSELLECK (wie Anm. 103), XXIII.

${ }^{106}$ C. MEIER, Der Wandel der politisch-sozialen Begriffswelt im 5. Jh. v. Chr., ABG 21, 1977, $7-41$ (vgl. DERS., Die Entstehung des Politischen bei den Griechen, Frankfurt a. M. 1980, 275-325).

${ }^{107}$ C. MEIER, Res publica amissa. Eine Studie zu Verfassung und Geschichte der späten römischen Republik, Frankfurt a.M. 1980, 55ff. Vgl. dazu auch K.-J. HÖLKESKAMP, Rekonstruktionen einer Republik, München 2004, 24ff.

${ }^{108}$ BLEICKEN (wie Anm. 69), 17 und 52; vgl. DERS., Art. „Freiheit II.2“, in: Geschichtliche Grundbegriffe 2, 1976, 430-435 (= DERS., Gesammelte Schriften, Bd. 1, Stuttgart 1998, 156-161) sowie DERS., Der Begriff der Freiheit in der letzten Phase der römischen Republik, HZ 185, 1962, 1-20 (= DERS., Gesammelte Schriften, Bd. 2, Stuttgart 1998, 663-682).

${ }^{109}$ Vgl. z. B. K.-J. HöLKESKAMP, Die Entstehung der Nobilität. Studien zur sozialen und politischen Geschichte der Römischen Republik im 4. Jh. v. Chr., Stuttgart 1987, 207ff. und 248ff.; DERS., Fides - deditio in fidem - dextra data et accepta. Recht, Religion und Ritual in Rom, in: C. BRUUN (Hg.), The Roman Middle Republic. Politics, Religion, and Historiography c. 400-133 B.C., Rom 2000, 223-250; H. KLOFT, liberalitas principis. Herkunft und Bedeutung. Studien zur Prinzipatsideologie, Köln u. a. 1970; L. R. LIND, The Idea of the Republic and the Foundations of Roman Political Liberty, in: C. DEROUX (Hg.), Studies in Latin Literature and Roman History, Bd. 4, Brüssel 1986, 44-108, bes. $81 \mathrm{ff}$;; H. MOURITSEN, Plebs and Politics in the Late Roman Republic, Cambridge 2001, bes. 9ff.; K. RAAFLaUB, Dignitatis contentio. Studien zur Motivation und politischen Taktik im Bürgerkrieg zwischen Caesar und Pompeius, München 1974; DERS., Freiheit in Athen und Rom. Ein Beispiel divergierender politischer Begriffsentwicklung in der Antike, HZ 238, 1984, 529-567 und DERS., Die Entdeckung der Freiheit. Zur historischen Semantik und Gesellschaftsgeschichte eines politischen 
durch den Dschungel (post)moderner und (post)strukturalistischer Modelle der Begriffs- und Diskursgeschichte, der historischen Semantik und der linguistischen Mentalitätengeschichte gebahnt. ${ }^{110}$

\section{Fazit: Römische Wertbegriffe?}

Der Exkurs in die Vergangenheit der altertumswissenschaftlichen Wertbegriffsforschung zeigt, daß der Begriff selbst wenn nicht obsolet, so doch höchst problematisch ist. Er wurde benutzt, um die zeitlosen römischen "Tugenden" der Pflichterfüllung und Treue, der Standhaftigkeit und Verläßlichkeit, der Autorität und der Würde zu feiern. Und er läuft heute Gefahr, angesichts der aktuellen Diskussionen um „europäische“ oder „westliche“ Werte, die es im Kampf gegen den islamistischen Terrorismus zu verteidigen gelte, wieder politisiert und ideologisiert zu werden. Die wissenschaftsgeschichtliche Rückbesinnung läßt es fraglich erscheinen, ob er als heuristische Kategorie dienen kann. Eher sollte bei Untersuchungen der römischen Diskurse über soziale und politische Kohäsion von ,Leitbegriffen' oder ,Sinnkonzepten ${ }^{\text {"111 }}$ gesprochen werden.

An die zentralen Konzepte der ,politisch-sozialen Begriffswelt“112 müssen klar definierte sozial-, politik-, kultur- und mentalitätsgeschichtliche Fragestellungen herangetragen werden. Die Untersuchungen dürfen sich nicht in Wortgeschichte und Lexikometrie erschöpfen. Vielmehr ist der Prozeß darzustellen, durch den ein Wort zu einem Begriff wurde und durch

Grundbegriffes der Griechen, München 1985. - Vgl. dazu auch HöLKESKAMP (wie Anm. 107), 24ff. und $50 \mathrm{ff}$.

${ }^{110} \mathrm{Vgl}$. hierzu etwa H.-E. BöDEKER (Hg.), Begriffsgeschichte, Diskursgeschichte, Metapherngeschichte, Göttingen 2002; D. BUSSE, Historische Semantik, Stuttgart 1987; D. BUSSE, W. TEUBERT, Ist Diskurs ein sprachwissenschaftliches Objekt? Zur Methodenfrage der historischen Semantik, in: DERS. u.a. (Hgg.), Begriffsgeschichte und Diskursgeschichte. Methodenfragen und Forschungsergebnisse der historischen Semantik, Opladen 1994, 10-28; U. DANIEL, Kompendium Kulturgeschichte. Theorien, Praxis, Schlüsselwörter, Frankfurt a. M. 2001, 345ff.; C. DUTT (Hg.), Herausforderungen der Begriffsgeschichte, Heidelberg 2003; F. HERMANNS, Sprachgeschichte als Mentalitätsgeschichte. Überlegungen zu Sinn und Form und Gegenstand historischer Semantik, in: A. GARDT u.a. (Hgg.), Sprachgeschichte des Neuhochdeutschen, Tübingen 1995, 69-101; A. LANDWEHR, Geschichte des Sagbaren. Einführung in die Diskursanalyse, Tübingen 2001; R. REICHARDT, Historische Semantik zwischen lexicométrie und New Cultural History, in: DERS. (Hg.), Aufklärung und Historische Semantik, Berlin 1998, 71-93 und DERS., Einleitung, in: DERS., E. SCHMITT (Hgg.), Handbuch politisch-sozialer Grundbegriffe in Frankreich 1680-1820, Bd. 1, 1985, 39-148.

${ }^{I I I}$ Vgl. K.-J. HöLKESKAMP u. a. (Hgg.), Sinn (in) der Antike. Orientierungssysteme, Leitbilder und Wertkonzepte im Altertum, Mainz 2003, 1 ff.

${ }^{112}$ MEIER, Wandel (wie Anm. 106). 
den seine Bedeutungen sich veränderten. Diesen Wandel der Bedeutungen, der vielfältige geschichtliche Erfahrungen und unterschiedliche Sachbezüge spiegelt, nachzuzeichnen, ist Aufgabe einer theoretisch reflektierten und wissenschaftsgeschichtlich sensibilisierten Forschung.

Eine solchermaßen verstandene Begriffsgeschichte ist nicht auf der Suche nach überzeitlichen Werten, sondern analysiert „geschichtliche Bewegung, wie sie sich in Begriffen spiegelt" und interpretiert Geschichte "durch ihre jeweiligen Begriffe". ${ }^{113}$ Als richtungweisende Vorbilder können nicht nur die inzwischen ,klassischen' althistorischen Untersuchungen von Christian Meier, Kurt Raaflaub, Jochen Bleicken und Karl-Joachim Hölkeskamp dienen, sondern auch - in transepochaler Perspektive neuhistorische Studien wie Willibald Steinmetz' Darstellung des Wandels politischer Handlungsspielraume in der Sprache und durch die Sprache im England vom späten 18. bis in die Mitte des 19. Jahrhunderts. ${ }^{114}$

${ }^{113}$ MeIER (wie Anm. 19), 797.

${ }^{114}$ W. STEINMETZ, Das Sagbare und das Machbare. Zum Wandel politischer Handlungsspielräume: England 1780-1867, Stuttgart 1993. 